This item was submitted to Loughborough's Research Repository by the author.

Items in Figshare are protected by copyright, with all rights reserved, unless otherwise indicated.

\title{
Characterization and application of aggregated porous copper oxide flakes for cupric source of copper electrodeposition
}

\section{PLEASE CITE THE PUBLISHED VERSION}

http://dx.doi.org/10.1016/j.matlet.2014.10.080

\section{PUBLISHER}

(C) Elsevier

\section{VERSION}

AM (Accepted Manuscript)

\section{PUBLISHER STATEMENT}

This work is made available according to the conditions of the Creative Commons Attribution-NonCommercialNoDerivatives 4.0 International (CC BY-NC-ND 4.0) licence. Full details of this licence are available at: https://creativecommons.org/licenses/by-nc-nd/4.0/

\section{LICENCE}

CC BY-NC-ND 4.0

\section{REPOSITORY RECORD}

Chen, Yuanming, Jianhui Lin, Tianyang Qiu, Wei He, Vadim V. Silberschmidt, Shouxu Wang, and Ze Tan. 2019. "Characterization and Application of Aggregated Porous Copper Oxide Flakes for Cupric Source of Copper Electrodeposition”. figshare. https://hdl.handle.net/2134/17465. 


\title{
Characterization and application of aggregated porous copper oxide flakes for cupric source of copper electrodeposition
}

\author{
Yuanming Chen ${ }^{\mathrm{a}, \mathrm{b}}$, Jianhui Lin ${ }^{\mathrm{a}}$, Tianyang Qiu ${ }^{\mathrm{b}}$, Wei $\mathrm{He}^{\mathrm{a}, \mathrm{c}, \mathrm{n}}$, Vadim V. Silberschmidt ${ }^{\mathrm{b}}$, \\ Shouxu Wang ${ }^{\mathrm{a}}$, Ze $\operatorname{Tan}^{\mathrm{c}}$ \\ a State Key Laboratory of Electronic Thin Films and Integrated Devices, University of Electronic Science and \\ Technology of China, Chengdu 610054, China \\ b Wolfson School of Mechanical and Manufacturing Engineering, Loughborough University, Loughborough \\ LE11 3TU, United Kingdom \\ C Research and Development Department, Guangdong Guanghua Sci-Tech Co., Ltd., Shantou 515000, China
}

\section{Abstract}

Copper oxide was prepared with thermal decomposition of basic copper carbonate to complement the concentration of cupric ions for copper electrodeposition in a plating system with insoluble anode. Copper oxide particles with a structure of aggregated porous flakes had a wide size distribution ranging from $100 \mathrm{~nm}$ to $100 \mu \mathrm{m}$. Copper oxide exhibited a dissolution rate of about $15 \mathrm{~s}$ in $12.5 \mathrm{vol} \% \mathrm{H}_{2} \mathrm{SO}_{4}$ with stable cupric concentration provided by rapid dissolution of copper oxide.

\section{Introduction}

Electronic products with the demand of miniaturization, multifunction and portability pursue high density interconnection (HDI) of printed circuit boards (PCB) for transmitting electrical signals in high speed [1,2]. Copper electrodeposition has good agreement with HDI microvias metallization due to its void-free filling in the features, minimal topography of the final copper surface, and controllable impurity incorporation in the plated copper film [3-5].

Phosphorized copper anodic material was generally used to complement the cupric ions consumed in electrochemical reaction since it could avoid excessive polarization and prevent direct immersion of copper particles into reacting solution [6], compared with pure copper anodic material. However, impure chemicals in phosphorized copper, released during electroplating process could influence the structure of copper deposits [7]. In addition, the change of size, topography and specific surface area of phosphorized copper during dissolved process could induce unstable current density and uneven distribution of electric fluxline, thereby resulting in weak plating uniformity of copper deposits $[2,8]$. Alternatively, a novel plating system with insoluble anode is employed for copper electrodeposition with high performance, where copper oxide is dissolved for the complement of cupric ions. Microstructure of copper oxide plays a significant role in the

\footnotetext{
${ }^{\mathrm{n}}$ Corresponding author at: State Key Laboratory of Electronic Thin Films and Integrated Devices, University of Electronic Science and Technology of China, Chengdu 610054, China. Tel./fax: p86 2883203218.

E-mail address: heweiz@uestc.edu.cn (W. He).
}

dissolving speed in plating solution but sometimes the size, topography and specific surface area of copper oxide are strongly dependent on the preparation methods. Various methods were used to synthesize copper oxide with different morphology [9]. In this work, copper oxide was prepared by thermal decomposition of solid-state basic copper carbonate. In addition, copper oxide was employed for the complement of consuming cupric ions to form fine copper deposits during electrochemical deposition.

\section{Experimental}

$\mathrm{CuSO}_{4} \times 5 \mathrm{H}_{2} \mathrm{O}(\geq 99.7 \mathrm{wt} \%)$ was dissolved in pure water at 80 ${ }^{\circ} \mathrm{C}$ and then filtered to further improve the level of purity. After adding polyethylene glycol (PEG) with an average molecular weight of $4000, \mathrm{NaHCO}_{3}$ was put into a vessel with $\mathrm{CuSO}_{4}$ solution under the condition of vigorous stirring at the temperature of

$70-80^{\circ} \mathrm{C}$. The stoichiometric ratio of $\mathrm{CuSO}_{4}$ and $\mathrm{NaHCO}_{3}$ was taken as 3:1. The concentration of PEG was $1 \mathrm{~g} / \mathrm{L}$. When $\mathrm{CO}_{2}$ was completely released, the mixture solution was let to stand for 30 min to obtain the precipitation of basic copper carbonate. Asreceived basic copper carbonate was successively cleaned with ethyl alcohol and pure water for 3 times, then separated by centrifugation at 1000-2000 rpm for $15 \mathrm{~min}$. Dry basic copper carbonate was put into a calciner for thermal decomposition at $500^{\circ} \mathrm{C}$ for $3 \mathrm{~h}$. A black copper-oxide powder product was finally obtained.

The feature micrographs of copper oxide particles were obtained using a scanning electron microscope (SEM). Size distribution of copper oxide particles in pure water was examined by laser particle 

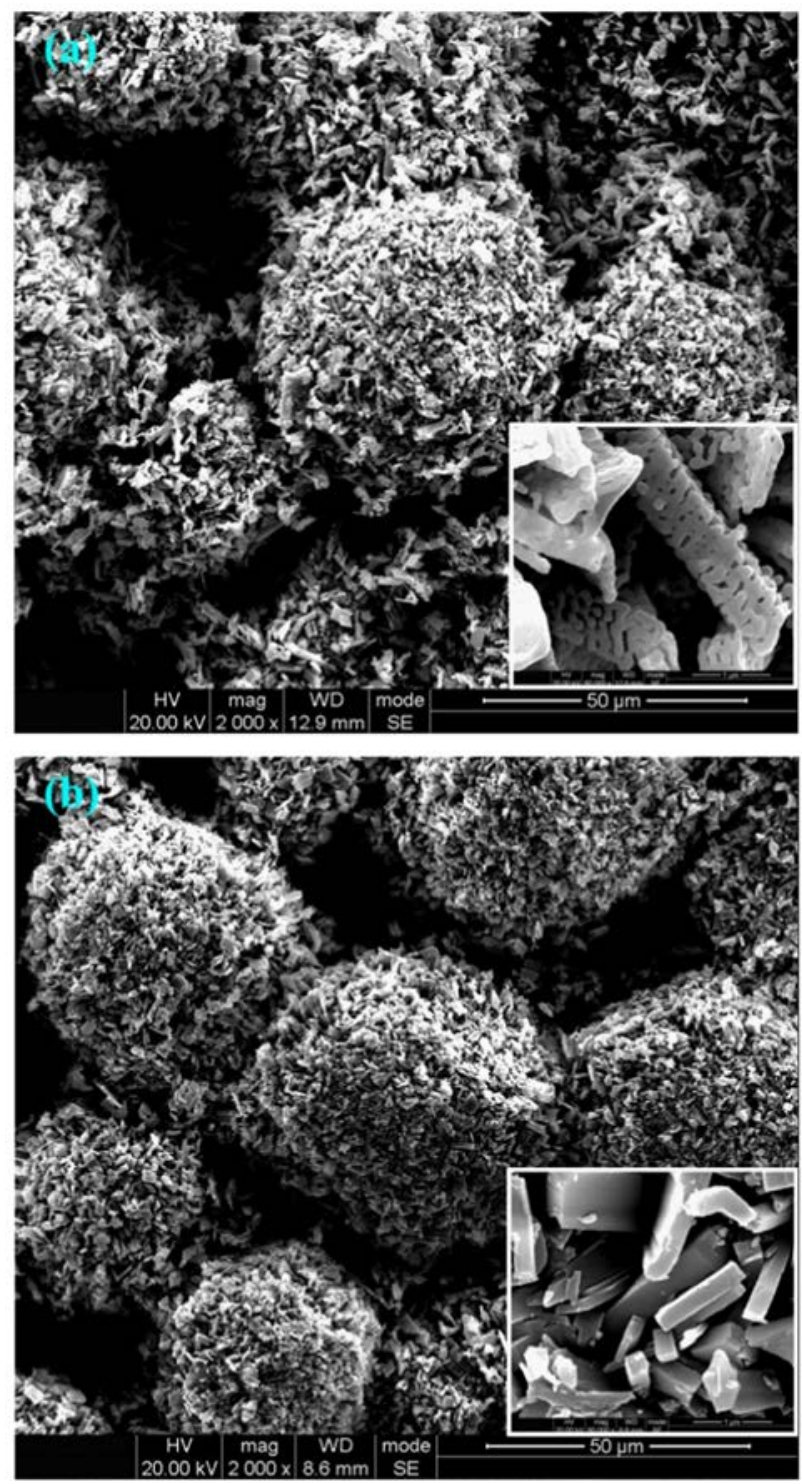

(c)
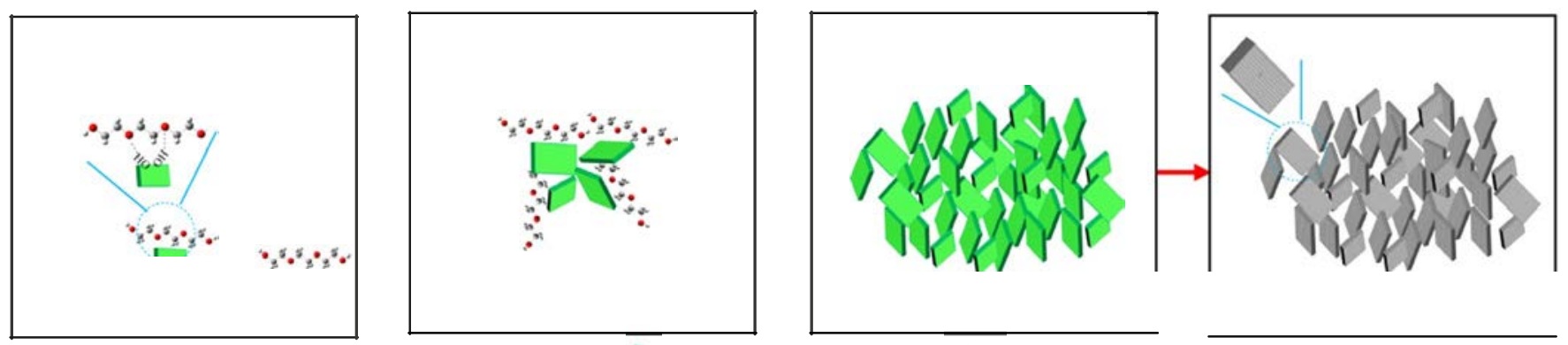

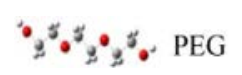
basic copper carbonate

copper oxide

Fig. 1. SEM micrographs (a and b) and formation mechanism (c) of copper oxide and basic copper carbonate.

size analyzer. The grain growth of copper oxide particles was monitored by X-ray diffraction spectra (XRD). Fourier-transform infrared (FT-IR) spectroscopy was used to determinate chemical composition of copper oxide. $4.2 \mathrm{~g}$ copper oxide was added to $80 \mathrm{~mL} \mathrm{H}_{2} \mathrm{SO}_{4}$ (12.5 vol\%) to measure the dissolution rate using an AUfOlAB potentiostat (AUf85266) with a two-electrode cell. A copper wire with a diameter of $1 \mathrm{~mm}$ was used as the working electrode.
A saturated mercurous sulfate electrode (SSE) was used as the reference electrode.

A plating system with insoluble anode was employed to form copper electrodeposition. The electrolyte for the electrochemical experiments contained $0.40 \mathrm{~mol} / \mathrm{L} \mathrm{CuSO}_{4} \cdot 5 \mathrm{H}_{2} \mathrm{O}$ and $1.80 \mathrm{~mol} / \mathrm{L}$ $\mathrm{H}_{2} \mathrm{SO}_{4}$ in pure water with additives of $0.7 \mathrm{mg} / \mathrm{L}$ bis-(sodium sulfopropyl)-disulfide (SPS), $20 \mathrm{mg} / \mathrm{L}$ ethylene oxide-propylene 
oxide co-polymer (EO/PO) and 60 ppm chloride ions. Copper oxide was used to retain the constant concentration of cupric ions in the plating solution. SEM and energy dispersive X-ray spectroscopy (EDS) were investigated to analyze the structure and composition of copper deposits.

\section{Results and discussion}

Copper oxide particles (Fig. 1a) exhibited nearly spherical appearance with aggregated porous flakes after the thermal decomposition of basic copper carbonate (Fig. 1b). During the formation of basic copper carbonate, PEG could act as a template direction agent to optimize growth orientation and growth rate $[10,11] . \mathrm{OH}^{-}$groups preferentially absorbed ether groups in PEG

a

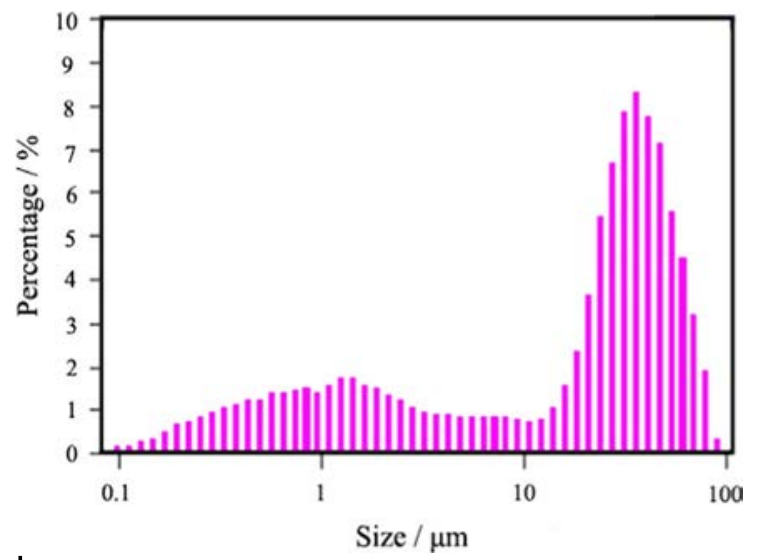

b

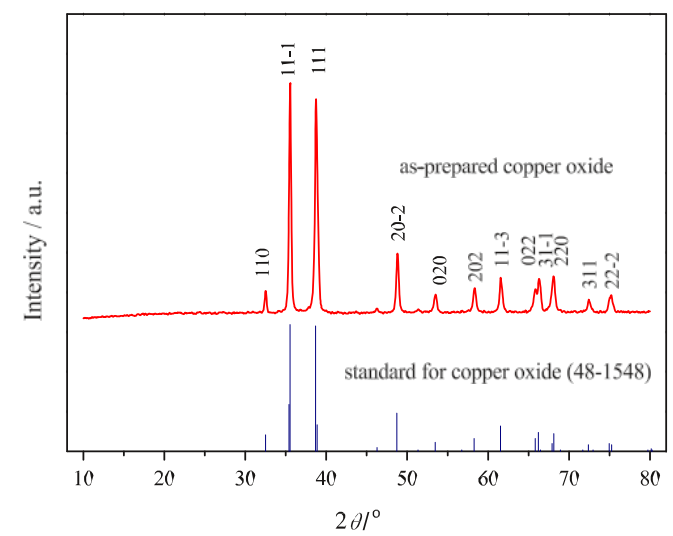

C

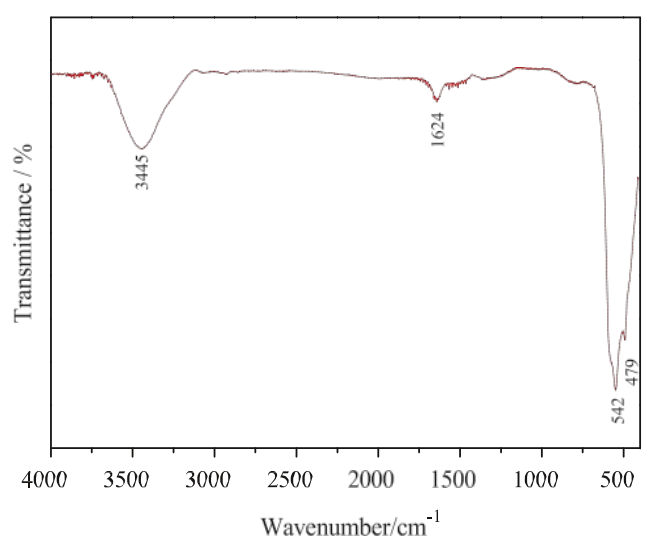

Fig. 2. Size distribution (a), XRD patterns (b) and FTIR spectrum (c) of copper oxide. polymeric chain, illustrated in Fig. 1c so that $\mathrm{Cu}^{2 \mathrm{P}}$ and $\mathrm{CO}_{3}^{2-}$ in the solution moved towards the long chain of the PEG to form the crystal growth of basic copper carbonate with a flake-like structure [12]. However, the presence of PEG could also lower the reactivity of basic copper carbonate, resulting from the hydrogen bonding strength between PEG and water for inhibiting the rapid movement of ions. On the other hand, the hydrophilic groups in the polymeric chain of PEG adsorbed at the surface of the crystal nuclei to prevent rapid growth of the particles. As basic copper carbonate grew mature, PEG and water molecules gradually departed from the particles which tended to form agglomerates in response to the minimum high surface energy [11,12]. Thus, aggregated basic copper carbonate flakes formed. Thermal decomposition of basic copper carbonate resulted in the emission of $\mathrm{CO}_{2}$ and water, thereby causing the porous structure and loose aggregation of the flakes.

Fig. 2a presented the size distribution of copper oxide particles. Aggregated copper oxide flakes had a wide size distribution ranging from $100 \mathrm{~nm}$ to $100 \mu \mathrm{m}$. Inspite of aggregation formation, small size copper oxide particles could also be measured since surrounding copper oxide flakes could escape from the surface of spherical aggregation. On the other hand, when copper oxide was immersed into pure water (polar solution), oxygen group of copper oxide could combine with hydrone to form hydrogen bonding, thereby inducing interaction force to make superficial copper oxide flakes disperse into the pure water.

All XRD peaks in Fig. 2b corresponded to the grain growth of copper oxide according to JCPDS (Joint Committee on Powder Diffraction Standards) card of copper oxide (JCPDS 48-1548).

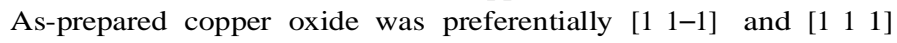
textured with stronger intensity. Fig. 2c displayed the FTIR spectrum of copper oxide particles. Copper oxide with $\mathrm{Cu}-\mathrm{O}$ stretching vibrations exhibited characteristic absorption bands at $479 \mathrm{~cm}^{-1}$ and $542 \mathrm{~cm}^{-1}$ [13]. The absorption at $3445 \mathrm{~cm}^{-1}$ indicated the presence of hydroxide group due to water absorption at the surface of copper oxide while the absorption peak at around $1624 \mathrm{~cm}^{-1}$ corresponded to $\mathrm{O}-\mathrm{H}$ bending vibrations combined with copper atoms. Thus, the formation of copper oxide compound was confirmed. XRD and FTIR indicated that as-prepared copper oxide could meet the requirement of high purity.

As shown in Fig. 3, potential of 12.5 vol\% $\mathrm{H}_{2} \mathrm{SO}_{4}$ solution was stable at $-0.510 \mathrm{~V}$ before adding as-prepared copper oxide. However, potential jumped to $-0.437 \mathrm{~V}$ in $2 \mathrm{~s}$ with the addition of copper oxide in the solution. Thereafter, potential of mixture solution increased slowly and finally reached a stable value of $-0.390 \mathrm{~V}$ at $16.9 \mathrm{~s}$. In addition, the color of mixture solution changed from black to blue due to the dissolution of copper oxide.

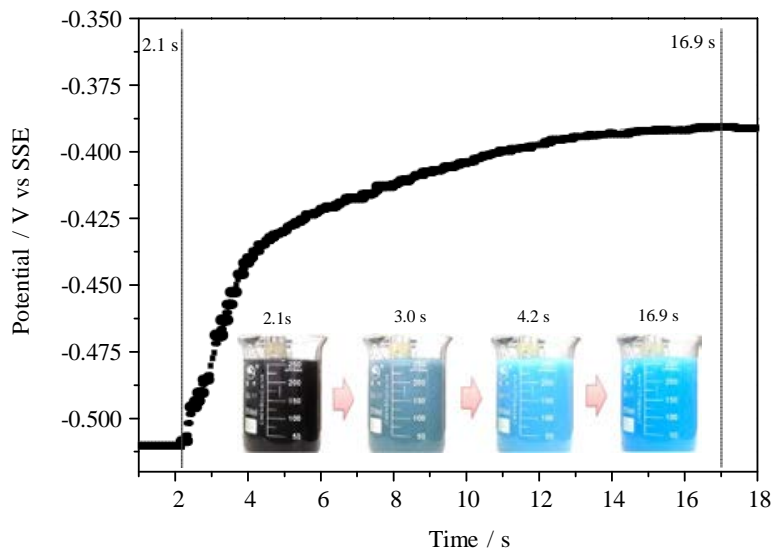

Fig. 3. Potential transient with the addition of copper oxide particles to $12.5 \mathrm{vol} \%$ $\mathrm{H}_{2} \mathrm{SO}_{4}$ : inset shows the color change of the solution. 

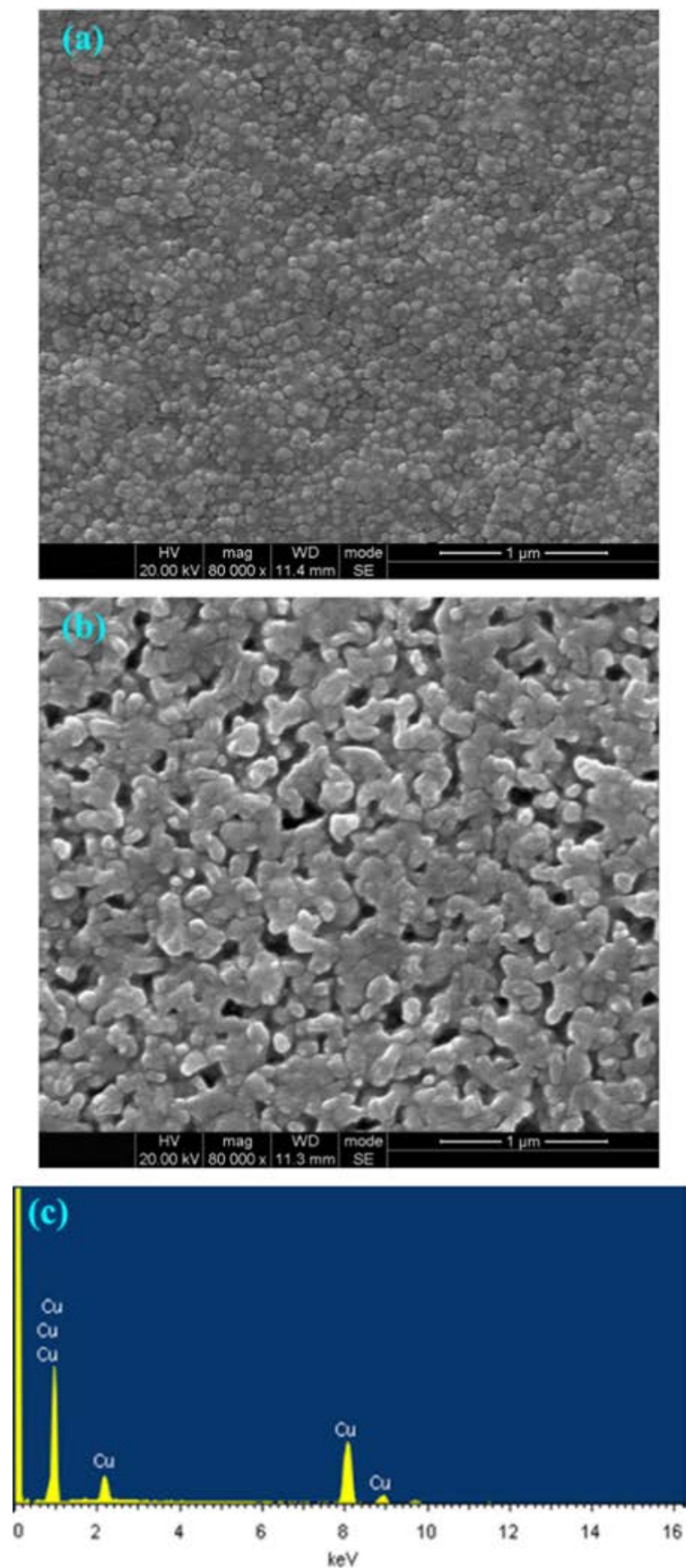

Fig. 4. SEM surface micrographs (a and b) and EDS (c) of copper deposits from the electrolytes with different cupric concentrations: a and $c-0.4 \mathrm{~mol} / \mathrm{L} ; \mathrm{b}-0.3 \mathrm{~mol} / \mathrm{L}$.

White bubble phenomenon stemmed from water diffusion into the solution since water could be generated from reaction between $\mathrm{H}_{2} \mathrm{SO}_{4}$ and copper oxide. Aggregated porous copper oxide flakes could accelerate their dissolution in two ways. $\mathrm{H}^{\mathbf{p}}$ could multidimensionally immerse into the flake aggregates of copper oxide so that reaction of dissolution synchronously occurred in internal and external particles. Moreover, copper oxide flakes with porous structure could provide high surface area to enhance their reacting chance with $\mathrm{H}^{+}$. Therefore, aggregated and porous structure in copper oxide could form a synergistic effect to improve the dissolving reaction in $15 \mathrm{~s}$.

Fig.4a and b displayed surface micrographs of copper deposits from the electrolytes with different cupric concentrations but with the same concentrations of additives as $0.7 \mathrm{mg} / \mathrm{L}$ SPS, $20 \mathrm{mg} / \mathrm{L}$ EO/PO and $60 \mathrm{ppm}$ chloride ions. Copper growth could be influenced during industrial copper electrodeposition if cupric ions were not rapidly complemented in a plating system with insoluble anode. As shown in Fig. 4b, copper deposits exhibited local aggregation of copper particles and surface voids of copper deposition were produced to induce large resistance when the cupric concentration decreased to $0.3 \mathrm{~mol} / \mathrm{L}$. Therefore, as-prepared copper oxide particles were added into the electrolyte to lead the cupric concentration to increase to $0.4 \mathrm{~mol} / \mathrm{L}$ and keep it stable during copper electrodeposition. In this way, copper deposits had good surface morphology with well-distributed even copper particles, as shown in Fig. 4a. EDS of Fig. 4c presented that copper deposits exhibited high purity when asprepared copper oxide particles were used to complement the cupric ions for electrodeposition.

\section{Conclusions}

Copper oxide was prepared by the thermal decomposition of aggregated basic copper carbonate flakes that were formed using PEG as a template. Aggregated copper oxide had a wide size distribution ranging from $100 \mathrm{~nm}$ to $100 \mu \mathrm{m}$. As-prepared copper oxide exhibited high purity and a rapid dissolution rate so that it could rapidly complement the cupric concentration in the electrolyte for fine copper growth during electrodeposition.

\section{Acknowledgments}

The authors gratefully acknowledge the support of Guangdong Innovative Research Team Program (No. 201301C0105324342), National Natural Science Foundation of China (No. 61474019) and Ph.D. Programs Foundation of Ministry of Education of China (No. 20120185110021), and we also express our sincere thanks to the support of China Scholarship Council (No. 201306070032).

\section{References}

[1] Dow WP, Li CC, Su YC, Shen SP, Huang CC, Lee C, et al. Electrochim Acta 2009;54:5894-901.

[2] Chen Y, He W, Chen X, Wang C, Tao Z, Wang S, et al. Electrochim Acta 2014;120:293-301.

[3] Kobayashi T, Kawasaki J, Mihara K, Honma H. Electrochim Acta 2001;47:85-9.

[4] Noh BI, Yoon JW, Lee BY, Jung SB. J Mater Sci: Mater Electron 2009;20:885-90.

[5] D'Urzo L, Schaltin S, Shkurankov A, Plank H, Kothleitner G, Gspan C, et al. J Mater Sci: Mater Electron 2012;23:945-51.

[6] Xu X, Liu H, Li W, Zhu L. Mater Lett 2011;65:698-701.

[7] Gondal MA, Qahtan TF, Dastageer MA, Salehb TA, Magandaa YW, Anjum DH. Appl Surf Sci 2013;286:149-55.

[8] Lin CT, Lin KL. J Mater Sci: Mater Electron 2004;15:757-62.

[9] Hong Z, Cao Y, Deng J. Mater Lett 2002;52:34-8.

[10] Zhao W, Yang Y, Hao R, Liu F, Wang Y, Tan M, et al. J Hazard Mater 2011;192:1548-54.

[11] Luévano-Hipólito E, Martínez-de la Cruz A, Yu QL, Brouwers HJH. Ceram Int 2014;40:12123-8.

[12] Xu J, Xue D. J Phys Chem B 2005:109:17157-61.

[13] Dubal DP, Dhawale DS, Salunkhe RR, Jamdade VS, Lokhande CD. J Alloys Compd 2010;492:26-30. 